\title{
IMPLEMENTASI PROGRAM SIMPAN PINJAM PEREMPUAN DI DESA MENDAWAI KECAMATAN MENDAWAI KABUPATEN KATINGAN
}

\section{Implementing women's lending program Mendawai village of mendawai subdistrict Regency of katingan}

\section{Masrukin* \\ Nur Akhsan Fitriadi}

Universitas Muhammadiyah Palangkaraya, Palangka Raya, Central Kalimantan, Indonesia

email:

masrukin@umpalangkaraya.ac.id

Kata Kunci:

Implementasi

Program

Perempuan

\section{Keywords:}

Implementation

Program

Women

\section{Accepted}

January 2018

Published

April 2018

\begin{abstract}
Abstrak
Peneltian ini difokuskan pada Implementasi Program Simpan Pinjam Perempuan di Desa Mendawai Kecamatan Mendawai Kabupaten Katingan. Tujuan dari penelitian ini ialah untuk mengetahui bagaimana Implementasi Program Simpan Pinjam Perempuan serta faktor pengehambat dan pendukung program Simpan Pinjam Perempuan didesa Mendawai Kecamatan Mendawai Kabupaten Katingan. Dalam penelitian yang mengangkat judul Implementasi Program Simpan Pinjam Perempuan, metode penelitian yang diambil menggunakan metode kualitatif. Adapun data yang didapatkan pada penelitian ini dikumpulkan melalui wawancara, observasi dan dokumentasi.
\end{abstract}

Hasil penelitian menunjukan bahwa dalam program simpan pinjam perempuan di Desa Mendawai Kecamatan Mendawai Kabupaten Katingan masih ada kendala yang dimiliki UPK maupun dari anggota simpan pinjam. Adapun saran yang bisa peneliti berikan pada pihak penyelenggaran progam simpan pinjam perempuan ini adalah (I) Diharapkan bisa memperhatikan lagi kendala yang ada dalam pelaksanaan program Simpan Pinjam Perempuan (SPP) agar program Simpan Pinjam Perempuan (SPP) bisa berjalan dengan baik.(2) Diharapkan UPK seharusnya bisa mengimput data setiap kelompok ke komputer sehingga apabila kelompok tersebut akan melakukan pinjaman pada periode kedua kelompok masyarakat tidak lagi harus melengkapi persyaratan seperti periode pertama (3) Diharapakan Untuk masalah fasilitas seharusnya UPK juga memperhatikan kondisi kantornya sebagai penunjang kinerja anggotanya.

\begin{abstract}
This study focused on implementing the Program of the women's borrow in Mendawai village, Mendawai District, Katingan Regency. The purpose of this research is to know how the implementation of the Save women's Program and the supporting factors and supporters of the women's Save borrow program in the village Mendawai District Mendawai District Katingan. In the study that raised the title of implementation of the women's Save lending Program, the method of research was taken using qualitative methods. The data obtained in this research is gathered through interviews, observations, and documentation.

The results showed that in the program of the women's borrowing in Mendawai village, Mendawai District, Katingan District, there are constraints of UPK and the members of the loan. The advice that researchers can give to the parties to the implementation of this female borrow is (I) It is expected to be aware of the constraints in implementing the women's Save (SPP) program for the Women's Save loan ( The SPP) can go well. (2) Hopefully UPK should be able to put the data of each group to the computer so that if the group will make loans in the second period of the community group no longer have to complete the requirements such as the first period (3) be expected For the problem of facility should UPK also pay attention to office conditions as supporting the performance of its members.
\end{abstract}

\section{PENDAHULUAN}

Program-program pembangunan yang telah dilaksanakan untuk mengatasi masalah kemiskinan seperti Bantuan Langsung Tunai (BLT), Raskin, kompensasi BBM, pengembangan desa tertinggal dan sebagainya. Namun, dari berbagai macam program yang sudah dilakukan pemerintah masih banyak kekurangan dalam pelaksanaannya dan masih belum bisa mengatasi kemiskinan, oleh sebab itu berbagai upaya masih terus menerus dilakukan pemerintah 
untuk mengatasi kemiskinan, dan kini pemerintahan desa juga harus ikut campur tangan untuk mengatasi kemiskinan di desanya masing-masing, salah satu kegiatan yang di lakukan pemerintah desa adalah dengan cara melajutkan program kerja yang pernah dilakukan oleh pemerintah pusat untuk desa yaitu, Program Nasional Pemberdayaan Masyrakat mandiri (PNPM mandiri). Melalui PNPM mandiri dilakukan perumusan kembali mekanisme upaya penanggulangan untuk mengatasi kemiskinan yang melibatkan masyarakat, mulai tahap perencanaan, peleksanaan hingga pengawasan dan evaluasi.

Pelaksanaan PNPM Mandiri Pedesaan berada dibawah binaan Direktorat Pemberdayaan Masyarakat dan Desa (PMD), Departemen Dalam Negeri. Program ini didukung dengan pembiayaan yang berasal dari alokasi Anggaran Pendapatan dan Belanja Negara (APBN), alokasi Anggaran Pendapatan dan Belanja Daerah (APBD), dana hibah dari sejumlah lembaga pemberi bantuan, dan pinjaman dari Bank Dunia. PNPM Mandiri Pedesaan menyediakan dana langsung dari pusat (APBN) dan daerah (APBD) yang disalurkan ke rekening kolektif desa di kecamatan. Masyarakat desa dapat mempergunakan dana tersebut sebagai hibah untuk membangaun sarana dan prasarana penunjang produktivitas desa, pinjaman bagi kelompok ekonomi untuk modal usaha bergulir, atau kegiatan sosial seperti kesehatan dan pendidikan.

Salah satu jenis kegiatan yang dibiayai melalui BLM PNPM Mandiri Pedesaan adalah kegiatan peningkatan kapasitas dan ketrampilan kelompok usaha ekonomi terutama bagi kelompok usaha yang berkaitan dengan produksi berbasis sumber daya lokal dan penambahan permodalan simpan pinjam untuk kelompok perempuan yang sering disebut Simpan Pinjam Perempuan (SPP).

Program Simpan Pinjam Perempuan (SPP) sudah banyak dijalankan dieberapa desa di Indonesia sejak dimulainya PNPM Mandiri Pedesaan oleh pemerintah pada tahun 2007 dan program tersebut mendapat respon yang baik di kalangan masyarakat pedesaan khususnya dipulau Jawa, kemudian PNPM Mandiri Pedesaan masuk ke Kalimantan pada tahun 2009 beserta beberapa program lainnya termasuk program Simpan Pinjam Perempuan (SPP) dan menyebar kebeberapa Kabupaten di Kalimantan salah satunya Kabupaten Katingan pada tahun $201 \mathrm{I}$ respon positif pun diterima oleh pihak pengelola karena program Simpan Pinjam Perempuan dianggap sangat membantu masyarakat pedesaan dalam mengembangkan usahanya khusunya bagi kaum perempuan yang ingin melakukan usaha, Program tersebut merepukan pinjaman modal usaha tanpa agunan dalam bentuk perguliran dengan kegiatan pengelolaan simpanan dan pinjaman melalui bentuk kelompok perempuan. Tidak ada batasan alokasi maksimal per desa, namun harus mempertimbangkan hasil verifikasi kelompok.

Berdasarkan observasi awal di Desa Mendawai Kecamatan Mendawai Kabupaten Katingan, daerah ini termasuk salah satu desa yang memperoleh bantuan PNPM Mandiri Pedesaan pada tahun 20II dan berakhir pada tahun 2014 dan kini program perguliran dari PNPM Mandiri Pedesaan dilanjutkan oleh pemerintah desa berdasarkan Undang-Undang (UU) Desa No. 6 tahun 2014 yang sudah disahkan oleh DPR-RI dan Pemerintah Pusat yang akan memberikan Desa alokasi dana untuk pembangunan khususnya program SPP. Di desa Mendawai sendiri sudah ada 6 kelompok yang mengikuti Program SPP yang rata-rata beranggotakan 5-8 orang perkelompoknnya.

Program SPP sangat membantu masyrakat desa dalam mengembangkan usahanyakhususnya kaum perempuan. Sebelum program SPP dilaksanakan di desa Mendawai Kec. Mendawai Kab. Katingan kelompok usaha masyarakat khususnya kaum perempuan yang memilki usaha kecil menengah hanya memiliki modal usaha yang sangat minim sehingga sangat sulit untuk mengembangkan usahanya dan kalah bersaing dengan mereka yang memiliki modal lebih besar. Maka, dengan adanya program SPP ini sangat membantu tambahan 
modal dan usaha kecil yang dijalankan hingga sekarang sedikit demi sedikit dapat di kembangkan. namun, terdapat beberapa factor penghambat terkait kebijakan dalam mengimplementasikan program SPP yang di anggap masyarakat kurang tepat dalam menjalankan program tersebut, sehingga membuat program kerja simpan pinjam perempuan dinilai masih kurang efektif untuk dijalankan bagi masyarakat miskin.

\section{METODOLOGI}

Metode penelitian yang digunakan adalah metode penelitian kualitatif karena metode ini merupakan sebuah menggambarkan, menjelaskan, dan mendeskripsikan suatu masalah. Oleh karena itu peneliti menggunakan jenis penelitian yang bersifat deskriptif agar lebih mudah untuk membuat gambaran yang bersifat faktual dan akurat mengenai fakta-fakta dilapangan yang terkait dengan fenomena atau masalah yang diteliti, yaitu mengetahui Pengimplementasian Program Kerja Desa Simpan Pinjam Perempuan di Desa Mendawai Kececamatan Mendawai Kabupaten Katingan.

\section{HASIL DAN PEMBAHASAN}

Implementasi program Simpan Pinjam Perempuan adalah kegiatan/aktifitas pengelolaan dana simpanan dan pengelolaan dana pinjaman yang dilakukan oleh kaum perempuan diDesa Mendawai Kecamatan Mendawai Kabupaten Katingan. Untuk peleksanaan implementasikan Program Simpan Pinjam Perempuan peneliti berpedaoman pada Model Implementasi Rippley dan Frangklin, dimana ada tiga perspektif yang harus di penuhi yaitu: (I) perspektif kepatuhan, (2) perspektif Kelancaran rutinitas, dan (3) perspektif yang mengarah kepada kinerja yang memuaskan semua pihak.

\section{Perspektif Kepatuhan}

UPK melakukan kegiatan sosialisasi kepada masyarakat untuk mengenalkan masyarakat tentang program SPP, selain itu UPK juga mengadakan pelatihan dan monitoring kepada masyarakat apabila ada kelompok masyarakat yang masih merasa bingung bagaimana mengelola kelompoknya agar kelompok yang sudah melakukan pinjaman bisa mengembangkan dan mengelola dana yang mereka pinjam dengan baik, kegiatan ini dilakukan UPK apabila ada kelompok yang bermasalah atau merasa kurang paham sehingga kegiatan ini bisa dilakukan kapan saja.

Kerjasama yang lakukan dengan pemerintah desa adalah memberikan izin kepada UPK untuk menjalankan Program Simpan Pinjam Perempuan (SPP) selain itu BKAD juga membantu UPK dalam menentukan kelompok masyarakat mana saja yang memenuhi syarat untuk melakukan pinjaman. UPK juga di awasi oleh BP UPK dalam Menjalankan program Simpan Pinjam Perempuan (SPP) agar program bisa berjalan sebagaimana mestinya. adapun kegiatan yang dilakukan UPK terkait proses pelaksanaan program Simpan Pinjam Perempuan sebagaimana ketentuan untuk melakukan pinjaman antara lain; membuat proposal, kemudian mengajukan ke UPK, peninjauan lokasi usaha oleh tim verifikasi, penyeleksian berkas oleh BKAD dan UPK dari tim verifikasi, penentuankelompok yang mendaptkan pinjaman terlebih dahulu, penyampaian hasil kekelompok yang mengajukan proposal.

Prosesnya dari UPK melakukan rapat dulu bersama pemerintahan desa untuk melakukan sosialisasi ke desa tentang pengenalan program Simpan Pinjam Perempuan setelah itu untuk melakukan pinjaman tentu masyarakat harus melengkapi persyaratan yang ditentukan kemudian menunggu hasil pencairan selama kurang lebih I bulan setelah itu masyarakat melakukapenyetoran ke UPK dalam I bulan sebanyak I kali, selain itu kami juga membenahi administrasi kelompok agar di dalam kelompok yang melakukan pinjaman tidak 
kesulitan dalam mengatur kelompoknya masingmasing.

Kelompok masyarakat juga menjelaskan tentang tahapan-tahapan melakukan Simpan Pinjam Perempuan. Pertama kami mengumpulkankan anggota kelompok dulu yang terdiri dari 5-10 orang kemudian kami membuat proposal dan melengkapi persyaratan yang ditentukan UPK kemudian kami menunggu hasil perangkingan proposal yang dilakukan UPK setelah itu barulah dana keluar dan kami bagikan kesetiap anggota kelompok sesuai dengan pinjaman yang kami ajukan. Kegiatan ini sudah dilaksanakan namun hasilnya belum maksimal.

2. Kelancaran Rutinitas

ada beberapa faktor penghambat dalam implementasi program Simpan Pinjam Perempuan (SPP), adalah masalah dana karena dana yang akan di pinjamkan masih sangat terbatas sehingga tidak bisa memenuhi permintaan masyarakat yang melakukan pinjaman secara bersamaan selain itu juga masalah tidak lengkapnya persyaratan proposal yang dibuat kelompok hal ini akan memperlambat proses pencairan dana. Anggota simpan juga mengeluhkan proses peminjaman di periode kedua karena harus mengajukan proposal sebagaimana pertama kali mengajukan proposal pinjaman. Selain hal itu juga berdasarkan hasil lapangan yang peneliti lihat fasilitas di kantor UPK juga masih kurang memadai ditambah lagi pegawai yang ada dikantor UPK juga masih sering tidak hadir diwaktu yang ditentukan (rapat).

Kelancaran rutinitas seperti prosedur pertemuan dengan anggota kelompok simpan pinjam maupun kendala-kendala yang dihadapi, pada bagian ini menjelaskan kendala-kendala yang dihadapi maupun prosedur dalam menjalankan program simpan pinjam perempuan di Desa Mendawai kecamatan Mendawai Kabupaten Katingan.
3. Presfektif pelaksanaan kinerja yang memuaskan semua pihak

Presfektif pelaksanaan yang mengarah kepada kinerja yang memuaskan semua pihak terutama penerima manfaat yang diharapkan, menurut Ripley dan Frangklin dalam Arifin Tahir (2014:96) yaitu setiap pelaksanaan kebijakan pada akhirnya bermuara kepada efektif tidaknya proses implementasi. Padahal pada awalnya tujuan program Simpan Pinjam Perepuan adalah untuk membantu masyarakat miskin dalam meningkatkankesejahteraannya tetapi pada kenyataannya masyarakat miskin yang tidak memiliki usaha tidak bisa ikut dalam melakuakn pinjaman.

UPK Kecamatan Mendawai sebagai pelaksana program Simpan Pinjam Perempuan (SPP) berupaya menjalankan sebaik mungkin program SPP untuk menjaga atau menghindari permasalahan yang dapat merugikan UPK dan Kelompok yang melakukan pinjaman. Dengan adanya persyaratan seperti izin usaha dan kartu identitas anggota kelompok UPK bisa lebih merasa aman jika anggota yang melakukan pinjaman datanya diketahui dan usahanya memang ada untuk menghindari penyalah gunaan program SPP.

Meskipun persyaratan dalam melakukan pinjaman di UPK sudah ditentukan, UPK masih kesulitan untuk menjalankan program tersebut karena banyak usaha masyarakat didesa Mendawai tidak memiliki izin selainn itu masyarakat yang ingin melakukan pinjaman juga tidak memiliki KTP, sehingga ini menjadi salah satu yang akan memperlambat proses berjalannya program SPP. UPK harus berkordinasi dengan pemerintah desa agar masyarakat yang ingain melakukan pinjaman hendaknya dibantu oleh pemerintah desa dalam hal pembuatan izin usaha dan KTP, agar UPK bisa dengan mudah memproses pinjaman yang dilakukan masyarakat. 


\begin{abstract}
UPK juga mempunyai permasalahan pendanaan mengingat dana yang ada di UPK terbatas UPK harus melakukan sistem perangkingan proposal yang diajukan kelompok yang akan melakukan pinjaman, sistem prengkingan melihat dari kelengkapan proposal yang di buat oleh masing-masing kelompok, proposal yang paling lengkap maka kelompok tersebut yang akan mendapatkan pinjaman terlebih dahulu dibandingakan kelompok yang proposalnya kurang lengkap, tetapi kelompok yang proposalnya tidak lengkap atau mendapatkan rangking dibawah tetap akan mendapatkan pinjaman hanya saja waktunya agak lebih lama atau setelah UPK mendapatkan Storan pertama dari kelompokkelompok yang melakukan pinjaman terlebih dahulu atau kelompok-kelompok yang
\end{abstract} mendapatkan rangking teratas. Dengan kebijakan ini diharapkan semua kelompok yang akan melakukan pinjaman bisa terpenuhi pendanaannya.

Kemudian, juga ditemukan bahwa menurut masyarakat persyaratan untuk melakukan program juga masih sulit karena untuk melakukan pinjaman di periode kedua mereka juga harus melengkapi persyaratan seperti periode pertama hendaknya apabila mereka sudah melakukan pinjaman pada periode pertama diperiode kedua mereka tidak lagi melengkapi persyaratan seperti periode pertama pinjaman. Namun UPK menjelaskan bahwa hal tersebut sudah ketentuan yang dilakukan adalah tidak lain hanya utntuk kelaancaran dalam menjalan program Simpan Pinjam Perempuan di desa Mendawai Kecamatan Mendawai Kabupaten katingan.

\section{KESIMPULAN}

I. UPK (unit Pelaksana Kegiatan) memang sudah berusaha menjalankan Program Simpan Pinjam Perempuan dengan baik dengan mengeluarkan berbagai kebijakan untuk mempermudah masyarakat dalam melakukan pinjaman, namun tetap saja tidak semua masyarakat yang bisa melakukan painjaman berdasarkan kebijakan yang dibuat UPK selain itu masih ada keluhan dari masyarakat yang ingin melakukan pijaman di periode kedua yaitu harus melengkapi persyaratan kembali Dalam impelementasi program Simpan Pinjam Perempuan (SPP), UPK bekerja sama dengan pemerintah desa, seperti Kepala Desa, BPD, BKAD,Tim Verifikasi, dan BP UPK. selain dengan pemerintahan desa UPK juga bekerja sama dengan masyarakat agar mereka mau melakukan pinjaman sehingga program Simpan Pinjam Perempuan (SPP) bisa berjalan.

2. Faktor yang menjadi kendala maupun penghambat yang dihadapi dalam pelaksanaan program simpan pinjam perempuan masalah dana, dana yang dimiliki UPK masih sedikit selain itu tidak memahaminya masyarakat dalam pembuatan proposal dan tidak lengkapnya proposal untuk melakukan pinjaman juga memperlambat proses pencairan dana, terdapat juga beberapa fasilitas di kantor yang kurang memadai dan pegawai yang sering tidak hadir pada saat rapat.

\section{REFERENSI}

Agustino, Leo. 2012. Dasar-Dasar Kebijakan Publik. Bandung: Alfabeta.

Hendar. 20I0. Manajemen perusahaan koperasi. Jakarta: Penerbit Erlangga.

Nasution, M.N. 2004. Manajemen Jasa Terpadu. Bogor : Alfabeta.

Pasolong, Harbani. 2007. Teori Administrasi Publik. Bandung: Alfabeta.

Ratminto \& Winarsih Septi Atik. 2008. Manajemen Pelayanan. Yogyakarta : Pustaka Pelajar. 
Sedarmayanti. 2009. Reformasi Administrasi Publik, Reformasi Birokrasi, Dan Kepemimpinan Masa Depan. Bandung: Refika Aditama.

Sumarsono, Sonny. 2004. Manajemen koperasi (teori dan praktek). Yogyakarta : Graha Ilmu.

Subarsono, AG. 2013. Analisis, Kebijakan publik. Yogyakarta : Pustaka belajar.

Tahir , Arifin. 2014. Kebijakan Publik Dan Transparansi Penyelenggaraan Pemerintah Daerah. Bandung: Alfabeta.

Tangkilisan, Nogi, Hessel. 2005. kebijakan dan Manajemen Otonomi Daerah. Yogyakarta: Lukman Offset.

Tjiptono, Fandy. 2014. Pemasaran Jasa -Prinsip, Penerapan Dan Penelitian. Yogyakarta : C.V Andi Offset. 